\title{
Resistivity Stability of Ga Doped ZnO Thin Films with Heat Treatment in Air and Oxygen Atmospheres
}

\author{
T. Prasada Rao, M. C. Santhosh Kumar
}

Advanced Materials Laboratory, Department of Physics, National Institute of Technology, Tiruchirappalli, India.

Email: prasadphd2011@gmail.com, santhoshmc@nitt.edu

Received December $1^{\text {st }}, 2011$; revised January $6^{\text {th }}, 2012$; accepted February $7^{\text {th }}, 2012$

\begin{abstract}
The effect of annealing in air and oxygen on structural, electrical and optical properties of gallium doped $\mathrm{ZnO}$ thin films was investigated. The X-ray diffraction patterns showed that the films were highly preferentially oriented along (002) plane. After the heat treatment in air and oxygen environments, the intensity of (002) peak was apparently improved. It was found that heat treatment in air atmospheres lead to increase in surface roughness of the film. The GZO films annealed in oxygen at $673 \mathrm{~K}$ exhibited low resistivity of $4.21 \times 10^{-3} \Omega \cdot \mathrm{cm}$, while the resistivity of film annealed in air showed a slightly higher value of $7.14 \times 10^{-3} \Omega \cdot \mathrm{cm}$. In addition to this, all films have good optical transmittance about $80 \%$ in the visible region. It is found from the photoluminescence studies that the broad visible emissions in GZO films originated from the intrinsic shallow traps $\left(\mathrm{V}_{\mathrm{Zn}}\right)$ and deep level vacancies $\left(\mathrm{Z}_{\mathrm{ni}}, \mathrm{O}_{\mathrm{Zn}}\right.$ and $\left.\mathrm{V}_{\mathrm{O}}\right)$.
\end{abstract}

Keywords: GZO Thin Films; Spray Pyrolysis; XPS; Optical Properties; Electrical Properties

\section{Introduction}

In recent years, $\mathrm{ZnO}$ films have been extensively studied due to its promising nature of replacing $\mathrm{GaN}$ in the blue and ultraviolet optoelectronic applications such as UV lasers, blue to UV light emitting diodes and UV detectors [1-3]. The notable properties of $\mathrm{ZnO}$ are its direct band gap of $3.37 \mathrm{eV}$ at room temperature and high exciton binding energy of $60 \mathrm{meV}$ which is higher than that of $\mathrm{GaN}(21 \mathrm{meV})$ and $\mathrm{ZnSe}(20 \mathrm{meV})$ [4]. When compared to $\mathrm{GaN}$ and $\mathrm{ZnSe}, \mathrm{ZnO}$ films can be deposited at a lower temperature, which is preferable for realizing integration of $\mathrm{ZnO}$ based optoelectronic devices using silicon-based microelectronic process. Moreover, it is believed that the $\mathrm{Ga}, \mathrm{Al}$ and In doped $\mathrm{ZnO}$ nanostructures possess more potential for diverse applications [5]. Among these elements, Ga has two major advantages. Most important one is the lower defect generation when $\mathrm{ZnO}$ is doped with $\mathrm{Ga}$ since the atomic radius of $\mathrm{Ga}$ is similar to that of $\mathrm{Zn}$. The gallium doped zinc oxide (GZO) has been relativity less studied than Al-doped $\mathrm{ZnO}$ (AZO). Doping is the most relevant issue for the design and realization of $\mathrm{ZnO}$-based devices. This issue in particular, is important for the applications of $\mathrm{ZnO}$ as TCO. By means of doping, good conductivities as well large ranges of transparency in the visible (VIS) and near UV range can be obtained $[6,7]$. Therefore, impurity doped zinc oxide $(\mathrm{ZnO})$ such as $\mathrm{Al}$ or $\mathrm{Ga}$-doped $\mathrm{ZnO}$, has recently gained much attention as an optoelectronic material [8-12]. GZO is more stable with respect to oxidation due to gallium's greater electronegativity in comparison with aluminium [13]. It has also been reported that heavily Ga-doped $\mathrm{ZnO}$ is more stable than Al-doped $\mathrm{ZnO}$ when subjected to moisture [14]. Moreover, recent studies have reported the use of $\mathrm{ZnO}$ as an air stable anode in an OLED, providing an additional evidence of GZO as a promising TCO for organic device applications [15].

In this study, we illustrate the results of our investigations on the influence of air and oxygen atmosphere annealing on the structural, electrical and optical properties of Ga doped $\mathrm{ZnO}(\mathrm{GZO})$ films prepared by spray pyrolysis. Comparisons of the stability of the electrical resistivity of GZO films are analyzed after heat treatment in air and oxygen.

\section{Experimental}

Spray pyrolysis is an effective method for the deposition of GZO thin films. The precursor solution for spray pyrolysis was prepared by dissolving an appropriate amount of zinc acetate dehydrate and gallium nitrate in the mixture of deionized water and ethanol at room temperature. In this mixture, ethanol concentration was $10 \mathrm{ml}$ in 100 $\mathrm{ml}$ solution. A few drops of acetic acid were added to aqueous solution to prevent the formation of hydroxides. The concentration of gallium was 3 at $\%$. The total concentration of the solution was maintained at $0.2 \mathrm{~mol} \cdot \mathrm{L}^{-1}$. The glass substrates were cleaned thoroughly with acetone, 
isopropanol and finally with deionized water with the help of an ultrasonic bath. The nozzle was at a distance of $20 \mathrm{~cm}$ from the substrate during deposition. The solution flow rate was held at constant rate $3 \mathrm{ml} / \mathrm{min}$. Air was used as the carrier gas at the pressure of 2 bar. When aerosol droplets approach nearer to the substrates, pyrolytic processes occur and highly adherent GZO films were formed. The GZO thin films were deposited at substrate temperature of $623 \mathrm{~K}$ with $350 \mathrm{~nm}$ thickness. The as deposited samples were annealed for 30 minutes at $673 \mathrm{~K}$ in oxygen and air. Higher oxidation temperatures could not be used due to the limitations of the glass substrates. The thickness was measured using Stylus profile meter. The structural properties were studied by X-ray diffraction measurements (XRD) using Rigaku D/Max ULTIMA III diffractometer with $\mathrm{CuK}_{\alpha}$ radiation $(\lambda=$ $1.5406 \AA$ ). The average dimensions of crystallites were determined by the Scherer method from the broadening of the diffraction peaks. The surface chemical analysis was investigated by X-ray photoelectron spectroscopy (XPS) with anylizer PHOIBOS HSA3500 100 R4 [HWtype 30:2] MCD-5 instrument. Al $K_{\alpha}(1486.61 \mathrm{eV})$ radiation was used as the excitation source. The surface morphology profiles of the samples were recorded using Nanoscope-E instrument in contact mode with a $\mathrm{Si}_{3} \mathrm{~N}_{4}$ cantilever of atomic microscope (AFM). Photo luminescence (PL) measurements were performed using the $325 \mathrm{~nm}$ line from a Xenon pulse lamp as the excitation source. Electrical properties, namely resistivity, Hall mobility, and carrier concentration were measured at room temperature using a standard Hall measurement system (Ecopia, Model: HMS-3000) in van der Pauw configuration.

\section{Results and Discussion}

\subsection{Structural Properties}

The diffractogram (Figure 1) of the GZO thin films annealed in different atmospheres shows that all the XRD patterns have prominent peak corresponding to $\mathrm{ZnO}(002)$ orientation. $\mathrm{Ga}$ may either exist in the form of $\mathrm{Ga}_{2} \mathrm{O}_{3}$ or substitute for the $\mathrm{Zn}$ atom in $\mathrm{ZnO}$ lattice, designated as $\mathrm{Ga}_{\mathrm{Zn}}$. No peak ascribing to $\mathrm{Ga}_{2} \mathrm{O}_{3}$ phase is identified from $\mathrm{XRD}$. This reveals that gallium is plausible to reside on zinc site in the hexagonal lattice [16]. It is clear that the films exhibit highly preferred orientation with c-axis perpendicular to the substrate surface. Essentially, only (002) phase is dominating in all the films, indicating high crystalline quality in the film. The crystallinity evaluated from the intensity of the (002) diffraction peak is enhanced by annealing regardless of the annealing atmosphere. There can be many reasons for enhancement in crystallinity after annealing.

One of them is the increase in self-texturing by annealing, so that most of the grains tend to have a (002) preferred orientation through self-texturing. The (002) peak position for as grown GZO film is at $2 \theta=34.308^{\circ}$ which is lower than the corresponding bulk value of $\mathrm{ZnO}$ $\left(2 \theta=34.503^{\circ}\right.$, JCPDS: 75 - 0576). It is observed that with annealing, the (002) peak position shifts towards the powder value of $\mathrm{ZnO}$. This indicates a change in stress in the films due to annealing process [17]. The peak position at lower value indicates a tensile stress in the film [18]. The residual stress along c-axis tends to lower the length of c-axis. During heat treatment these crystallites gain enough diffusion/activation energy and small crystallites migrate to relatively equilibrium sites in the crystal lattice with lower surface energy, since the surface energy for (002) orientations is minimum for $\mathrm{ZnO}$ [19]. Thus, the growth orientation develops in one crystallographic direction (002) leading to a larger grain size. The annealing treatment also reduces the trap states thereby improving the crystallinity of the film. The full width at half maximum (FWHM) with $\pm 0.1 \%$ accuracy is found to vary with the annealing atmosphere, which can be attributed to the coalescences of grains in high temperature [20]. To estimate the grain size of GZO films Scherer's formula was employed. The values of $2 \theta$, FWHM, Roughness (R), grain size (XRD) and particle size (AFM) are shown in Table 1.

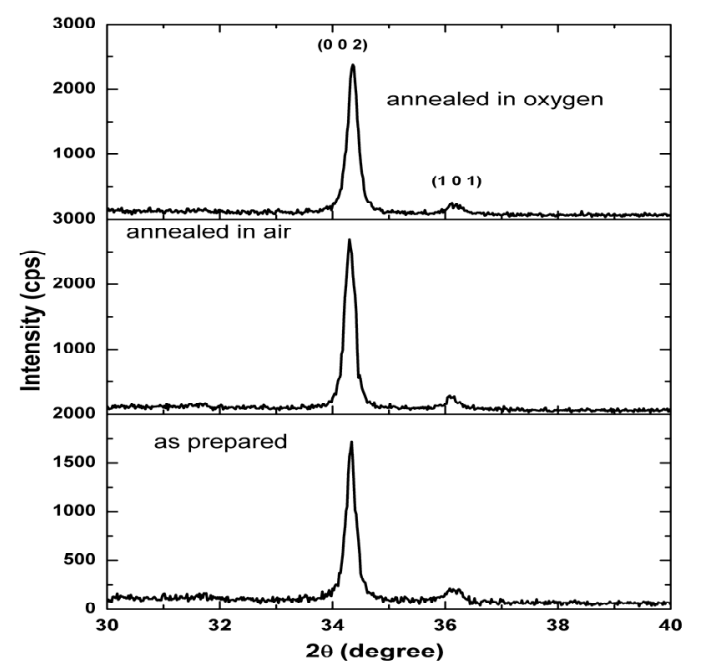

Figure 1. X-ray diffraction (XRD) patterns of GZO films.

Table 1. Calculated values of $2 \theta$, FWHM, r.m.s roughness (R) and grain size.

\begin{tabular}{cccccc}
\hline Sample & $\begin{array}{c}2 \theta \\
\text { degree }\end{array}$ & $\begin{array}{c}\text { FWHM } \\
\text { degree }\end{array}$ & $\begin{array}{c}\mathrm{R} \\
(\mathrm{nm})\end{array}$ & $\begin{array}{c}\text { Grain size } \\
(\mathrm{nm}) \mathrm{XRD}\end{array}$ & $\begin{array}{c}\text { Particle size } \\
(\mathrm{nm}) \\
\text { AFM }\end{array}$ \\
\hline Asprepare & 34.30 & 0.1909 & 19.0 & 43.5 & 159.5 \\
$\begin{array}{c}\text { Annealed in } \\
\text { air }\end{array}$ & 34.32 & 0.1857 & 27.0 & 44.8 & 173.6 \\
$\begin{array}{c}\text { Annealed in } \\
\text { oxygen }\end{array}$ & 34.35 & 0.1810 & 20.0 & 44.0 & 165.0 \\
\hline
\end{tabular}


The surface morphology of the samples was investigated using AFM and shown in Figure 2. The images (micrographs) are obtained in contact mode taken over a scale of $1 \times 1 \mu \mathrm{m}^{2}$. From the Figure 2, it is observed that the particles on the surface of all the films are irregular in nature, with some voids which arises from the aggregation of grains due to the movement of grain boundaries. The particle size calculated from the AFM data is shown in Table 1. The values are found to be larger than the grain size calculated from XRD data. This may be due to the aggregation of smaller grains which form bigger clusters on the surface of the films. From the Table 1, the average surface roughness of air annealed films is $27 \mathrm{~nm}$. This indicates that heat treatment in air can increase surface roughness of GZO film significantly. However, the average surface roughness does not vary much with annealing in oxygen atmosphere.

The surface composition of films was determined using XPS technique. The XPS spectra of the GZO films (Figure 3) show that the binding energy (BE) of each constituent element was positioned at $1117.72 \mathrm{eV}\left(\mathrm{Ga} 2 \mathrm{p}_{3 / 2}\right)$, $1022.23 \mathrm{eV}\left(\mathrm{Zn} 2 \mathrm{p}_{3 / 2}\right)$ and $530.9 \mathrm{eV}(\mathrm{O} 1 \mathrm{~s})$ as calibrated to $285.43 \mathrm{eV}(\mathrm{C} 1 \mathrm{~s})$.

The binding energy of Ga2 $\mathrm{p}_{3 / 2}$ is shown in Figure 3. The broadening of oxygen spectrum (Figure 3 ) is believed to be composed of two components located around $531 \mathrm{eV}$ and $532 \mathrm{eV}$ respectively. The low $\mathrm{BE}$ component is ascribed to covalently bonded oxygen in $\mathrm{ZnO}$ structure (lattice oxygen) while the high $\mathrm{BE}$ is attributed to the adsorbed oxygen [21-23]. The higher binding energy at 532 $\mathrm{eV}$ is usually attributed to chemisorbed or dissociated oxygen or $\mathrm{OH}$ species on the surface of the $\mathrm{ZnO}$ thin film, such as adsorbed $\mathrm{H}_{2} \mathrm{O}$ or adsorbed $\mathrm{O}_{2}$ [24]. Binding energy of $\mathrm{O} 1 \mathrm{~s}$ of as prepared, air annealed and oxygen annealed are $532.05 \mathrm{eV}, 532.33 \mathrm{eV}$ and $531.43 \mathrm{eV}$ respecttively. The binding energy of $\mathrm{O} 1 \mathrm{~s}$ is high when heat

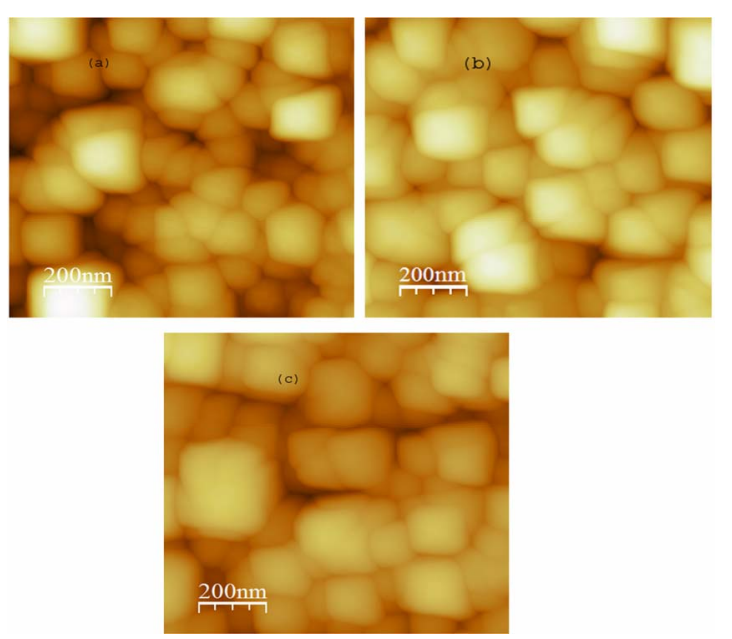

Figure 2. AFM surface morphology of GZO films (scan area $1 \times 1 \mu^{2}$ ) (a) as prepared, (b) annealed in air and (c) annealed in oxygen.
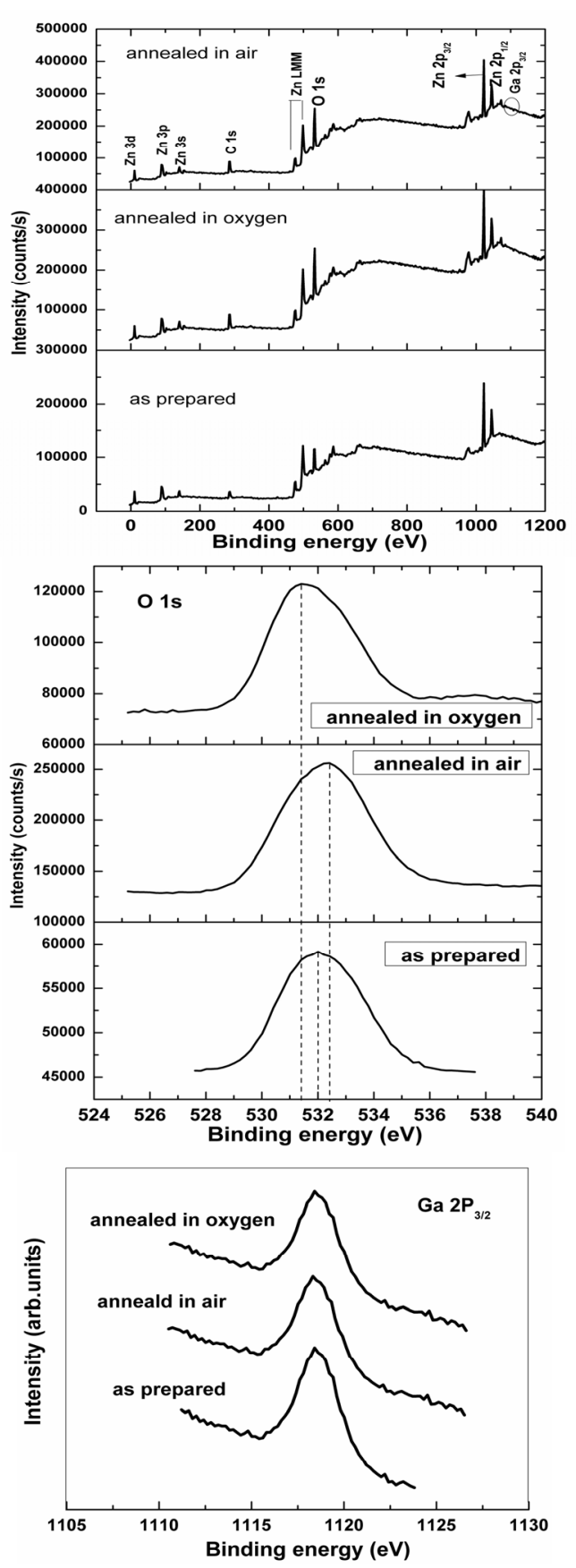

Figure 3. XPS spectra of GZO films.

treatment carried out in air. This O1s peak at binding energy of $532.33 \mathrm{eV}$ is clearly indicating the presence of chemisorbed oxygen in the samples. During annealing in oxygen ambient, oxygen vacancies are complemented dominantly by chemisorption process and this combines with sufficient $\mathrm{Zn}$ atoms to form new $\mathrm{ZnO}$ [25], resulting in the decrease of oxygen chemisorption i.e. decrease in oxygen binding energy. This chemisorption effect on the surface of the films is negligible in the other ambient such as high vacuum, inert gases and nitrogen $[26,27]$. 


\subsection{Electrical Properties}

The decrease in resistivity of GZO films compared with $\mathrm{ZnO}$ films is attributed to the replacement of $\mathrm{Zn}^{2+}$ by $\mathrm{Ga}^{3+}$ ions which introduce a large number of electrons in the doped films. The electrical resistivity, carrier concentration and mobility of GZO thin films annealed in different atmospheres are shown in Table 2 . The resistivity of as deposited films is found to be $5.00 \times 10^{-3} \Omega \cdot \mathrm{cm}$. The resistivity of GZO films decreased to $4.21 \times 10^{-3}$ $\Omega \cdot \mathrm{cm}$ with annealing in oxygen atmosphere.

From the structural studies, it is clear that the grain size of the GZO films increases during air annealing. The increase in grain size in turn decreases the grain boundary scattering effect. Consequently, a decrease in resistivity is expected. However, from the Table 2, it is seen that the resistivity is increased to $7.14 \times 10^{-3} \Omega \cdot \mathrm{cm}$ and the carrier concentration decreased to $4.62 \times 10^{19} \mathrm{~cm}^{-3}$. The resistivity of GZO films annealed in air is higher than that of the as-deposited sample, but the resistivity decrease in oxygen is smaller than that as-deposited sample. The variation in resistivity of GZO thin films is mainly due to the change in the concentration of oxygen vacancies. Ahn et al. observed that $\mathrm{O}_{\mathrm{II}}$ component decreases after annealing in oxygen or nitrogen which is related to the concentration of oxygen vacancies and the GZO films annealed in oxygen have the lower value of $\mathrm{O}_{\mathrm{II}}$ component [28]. After heat treatment, the changes in resistivity of GZO film can be explained by the chemisorptions of oxygen species at the grain boundaries. In general, the chemisorption of oxygen species at the grain boundaries may act as trapping sites and form potential barriers [29] and thereby decrease in the carrier concentration. On the other hand, the oxygen species scatter along the grain boundaries and occupy the oxygen vacancies in the film. Eventually, the chemisorbed oxygen onto the grain boundaries forms electron traps which reduce the carrier concentration considerably [30]. This leads to increase in resistivity of films. The binding energy values of oxygen are a measure of the chemisorbed oxygen in the films. The binding energy values are calculated from XPS studies. The oxygen (O1s) binding energy values for air annealed $(532.33 \mathrm{eV})$ film is higher than that of both as deposited $(532.05 \mathrm{eV})$ and oxygen annealed $(531.43 \mathrm{eV})$ films. This indicates that the chemisorption of oxygen effect is dominating in air annealed films. Hence, the resistivity is increased and carrier concentration decreased for air annealed films. On the other hand in oxygen annealed films, the oxygen $(\mathrm{O} 1 \mathrm{~s})$ binding energy is close to $531 \mathrm{eV}$, which suggests that the trapping effect of chemisorbed oxygen is weak. This leads to improvement in electrical properties of oxygen annealed GZO films.

\subsection{Optical Properties}

Figure 4 shows the transmission spectra in the wavelength range of $300-1200 \mathrm{~nm}$ for as grown and annealed GZO films at different annealing atmosphere. From the spectra, it is clear that all films exhibit a transmission of about $80 \%$ in the visible range. Transmission, however, falls very sharply in the UV region due to the onset of fundamental absorption. A slight decrease in average transmission is observed in the sample annealed in air and is attributed to increase of surface roughness. The optical transmittance of a film is known to depend strongly on its surface morphology. It is well known that annealing TCO films in an oxygen atmosphere improves their transmittance. Absorption due to an interband transition of $\mathrm{ZnO}$ occurs in the wavelength range from $340 \mathrm{~nm}$ to $380 \mathrm{~nm}$. The absorption coefficient $\alpha$ is calculated from the relation [31]. As a direct band gap semiconductor, the optical band gap $\left(\mathrm{E}_{\mathrm{g}}\right)$ and optical absorption coefficient $(\alpha)$ of GZO thin film are correlated using formula [32]. In the case of air annealing, the absorption band edge moved slightly towards the longer wavelength side (red shift) compare to as-deposited samples. In other words, the Burstein-Moss effect [33] is weak as the carrier concentration is lowered by annealing. It is well known that the band gap can be increased with the increase in carrier concentration due to the Burstein-Moss (BM) shift [34, 35]. From Figure 4, it is observed that the optical band gap values are same for the as-deposited and oxygen annealed samples with $\pm 0.06 \%$ error.

Photoluminescence (PL) is very sensitive to the quality of crystal structure and to the presence of defects. The band-to-band excitation of $\mathrm{ZnO}$ promotes electrons from the valence band to the conduction band, leaving holes in the valence band [36]. The holes migrate from the valence band to deep levels and recombination occurs between electrons from either the conduction band or shallow donor levels and trapped holes on deep levels [37]. Basically, the PL of $\mathrm{ZnO}$ is related to the presence of holes in the valence band. Room temperature PL spectra of the GZO thin films measured using Xenon lamp of $325 \mathrm{~nm}$ as excitation source is shown in Figure 5. The

Table 2. Variation of resistivity $(\rho)$, carrier concentration $(n)$, mobility $(\mu)$ and band gap of GZO films with annealing atmosphere.

\begin{tabular}{ccccc}
\hline Sample & $\rho(\Omega \cdot \mathrm{cm})$ & $n\left(\mathrm{~cm}^{-3}\right)$ & $\mu\left(\mathrm{cm}^{2} / \mathrm{Vs}\right)$ & $\mathrm{E}_{\mathrm{g}}(\mathrm{eV})$ \\
\hline Asprepare & $5.00 \times 10^{-3}$ & $6.58 \times 10^{19}$ & 18.99 & 3.28 \\
$\begin{array}{c}\text { Annealed in } \\
\text { air }\end{array}$ & $7.14 \times 10^{-3}$ & $4.62 \times 10^{19}$ & 18.94 & 3.26 \\
$\begin{array}{c}\text { Annealed in } \\
\text { oxygen }\end{array}$ & $4.21 \times 10^{-3}$ & $6.70 \times 10^{19}$ & 22.15 & 3.28 \\
\hline
\end{tabular}



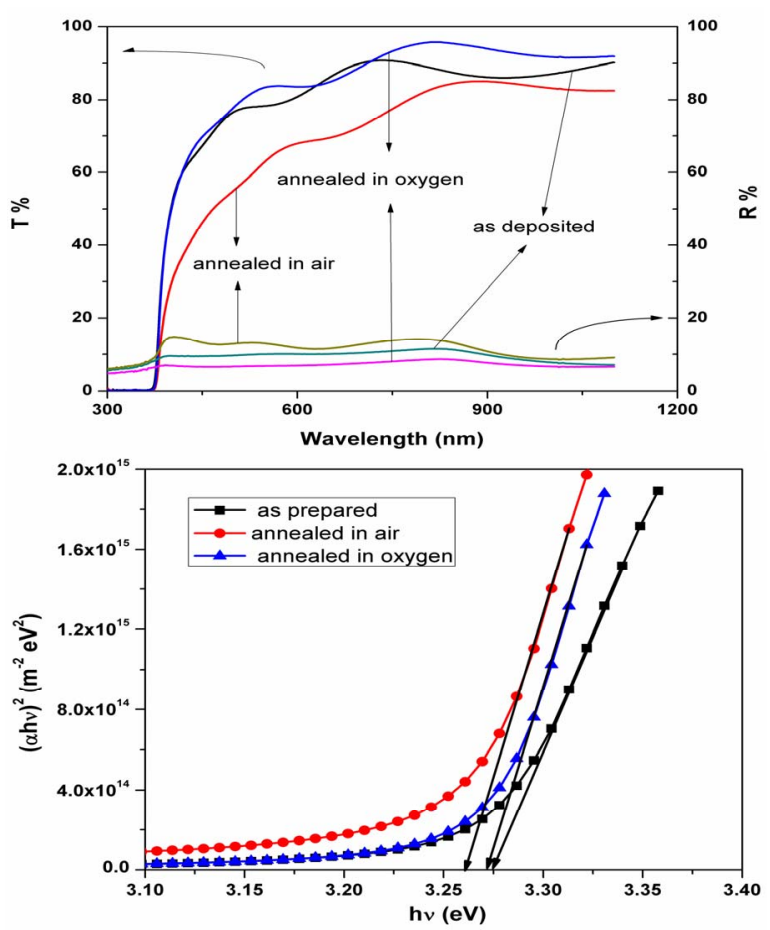

Figure 4. Transmission, reflectance and $(\alpha \mathrm{h} v)^{2}$ versus hv spectra of GZO films.

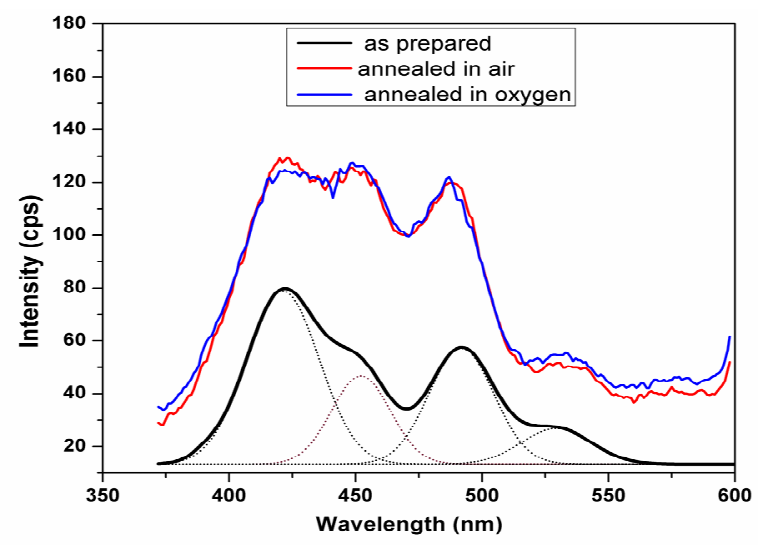

Figure 5. PL emission spectra of GZO films (dashed lines indicates the Gaussian deconvolution components).

PL emission spectra of as deposited GZO as well as annealed samples are broad and it can be deconvoluted (Gaussian deconvolution) into four bands, $419 \mathrm{~nm}(2.96$ $\mathrm{eV}), 452 \mathrm{~nm}(2.74 \mathrm{eV}), 491 \mathrm{~nm}(2.52 \mathrm{eV})$ and $530 \mathrm{~nm}$ $(2.34 \mathrm{eV})$. These results are different from the earlier reports on GZO thin films [38-40]. The violet luminescence at $419 \mathrm{~nm}(2.96 \mathrm{eV})$ is probably due to radiative defects related to the interface traps existing at the grain boundaries and emitted from the radiative transition between this level and the valence band [41]. There is a strong and broad green emission band centered at $491 \mathrm{~nm}$ $(2.52 \mathrm{eV})$, which may originate from the commonly assumed recombination of the photoexcited holes with the electrons occupying the singly ionized oxygen vacancies [42]. The green-peak near $2.52 \mathrm{eV}$ is the widely observed defect related emission in $\mathrm{ZnO}$ [43]. Egelhaaf et al. [44] reported that, this kind of defect related luminescence has the origin of radiative transitions between shallow donors (related to oxygen vacancies) and deep acceptors ( $\mathrm{Zn}$ vacancies). The emission at $530 \mathrm{~nm}(2.34 \mathrm{eV})$ originates from the defect level of antisite oxygen $\left(\mathrm{O}_{\mathrm{Zn}}\right)$. According to Ratheesh Kumar et al. [45], this emission was due to the transition from the conduction band to an acceptor level of antisite oxygen $\left(\mathrm{O}_{\mathrm{Zn}}\right)$. The peak at $452 \mathrm{~nm}(2.72$ $\mathrm{eV}$ ) is blue emission, which originates from the defect emission of oxygen vacancies [46] and it is close to previous reported value of $2.66 \mathrm{eV}$ [47]. The PL peaks of annealed films in both atmospheres showed broad emission peaks in violet and blue-green spectral region. The intensity of the emission peaks is found to be increasing with annealing. The enhancement of PL intensity of annealed films can be attributed to the improvement in crystallinity. The improved crystallinity reduces the recombination centers in the films. Consequently, there is a decrease in non-radiative recombination and increase in radiative recombination for non-equilibrium photogenerated carriers [48]. According to Wang et al. [49], the enhancement in green emission is attributed to the chemisorptions of oxygen. However, in our case the intensity of other emission peaks also increased after annealing. XPS results of O1s showed low binding energy (531.43 $\mathrm{eV}$ ) for oxygen annealed films, which is an indication of reduction in chemisorptions of oxygen. The intensity of green emission peak of oxygen annealed film is almost equal to intensity of air annealed films. Hence, the intensity enhancement of green emission in the present study is only due to the improved crystallinity. Irrespective of the annealing atmosphere, both air annealed and oxygen annealed samples showed similar bahaviour in PLranging between $420 \mathrm{~nm}$ and $530 \mathrm{~nm}$. This indicates that both the intrinsic shallow traps $\left(\mathrm{V}_{\mathrm{Zn}}\right)$ and deep level vacancies $\left(\mathrm{Z}_{\mathrm{n}}, \mathrm{O}_{\mathrm{Zn}}\right.$ and $\left.\mathrm{V}_{\mathrm{O}}\right)$ are being affected in $\mathrm{ZnO}$ [50] after the heat treatment. From the above discussion, it is confirmed that both the intrinsic traps and deep level vacancies are the most important factors that causes the broad visible emission from GZO.

\section{Conclusion}

The physical properties of GZO thin films prepared by spray pyrolysis were studied after heat treatment in air and oxygen atmospheres. The GZO thin films are polycrystalline with a preferred orientation (002). The crystallinity of GZO films improves after annealing treatment. It was found that from XPS studies, chemisorption of oxygen into the grain boundaries was predominant when heat treatment was carried out in air. The resistivity of GZO films annealed in air is higher than that of the 
as-deposited sample, but the resistivity decrease in oxygen is smaller than that as-deposited sample. It was found that the no change in optical band gap of oxygen annealed GZO thin films. PL studies were used to identify some intrinsic defect levels in GZO. It was found that PL intensity increases with heat treatment in both the air and oxygen atmospheres. It was confirmed that both the intrinsic traps and deep level vacancies were the most important factors that causes the broad visible emission.

\section{REFERENCES}

[1] R. F. Service, "Will UV Lasers Beat the Blues?" Science, Vol. 276, No. 5314, 1997, p. 895. doi:10.1126/science.276.5314.895

[2] D. P. Norton, Y. W. Heo, M. P. Ivill, K. Ip, S. J. Pearton, M. F. Chisholm and T. Steiner, "ZnO: Growth, Doping \& Processing," Materials Today, Vol. 7, No. 6, 2004, pp. 34-40. doi:10.1016/S1369-7021(04)00287-1

[3] S. J. Pearton, D. P. Norton, K. Ip, Y. W. Heo and T. Steiner, "Recent Progress in Processing and Properties of ZnO," Progress in Materials Science, Vol. 50, No. 3, 2005, pp. 293-340. doi:10.1016/j.pmatsci.2004.04.001

[4] B. Lin, Z. Fu and Y. Jia, "Green Luminescent Center in Undoped Zinc Oxide Films Deposited on Silicon Substrates," Applied Physics Letters, Vol. 79, No. 7, 2001, pp. 943-945. doi:10.1063/1.1394173

[5] J. Zhong, S. Muthukumar, Y. Chen, Y. Lu, H. M. Ng, W. Jiang and E. L. Garfunkel, "Ga-Doped ZnO Single-Crystal Nanotips Grown on Fused Silica by Metalorganic Chemical Vapor Deposition," Applied Physics Letters, Vol. 83, No. 16, 2003, pp. 3401-3403. doi:10.1063/1.1621729

[6] B. E. Sernelius, K. F. Berggren, Z. C. Jin, I. Hamberg and C. G. Granqvist, "Band-Gap Tailoring of $\mathrm{ZnO}$ by Means of Heavy Al Doping," Physical Review B, Vol. 37, No. 17, 1988, pp. 10244-10248. doi:10.1103/PhysRevB.37.10244

[7] H. Fujiwara and M. Kondo, "Effects of Carrier Concentration on the Dielectric Function of $\mathrm{ZnO}: \mathrm{Ga}$ and $\mathrm{In}_{2} \mathrm{O}_{3}$ : Sn Studied by Spectroscopic Ellipsometry: Analysis of Free-Carrier and Band-Edge Absorption," Physical Review $B$, Vol. 71, No. 7, 2005, pp. 1-10. doi:10.1103/PhysRevB.71.075109

[8] V. Bhosle, A. Tiwari and J. Narayan, "Metallic Conductivity and Metal-Semiconductor Transition in Ga-Doped ZnO," Applied Physics Letters, Vol. 88, No. 3, 2006, Article No. 032106. doi:10.1063/1.2165281

[9] J. De Merchant and M. Cocivera, "Preparation and Doping of Zinc Oxide Using Spray Pyrolysis," Chemistry of Materials, Vol. 7, No. 9, 1995, pp. 1742-1749. doi:10.1021/cm00057a026

[10] P. Nunes, E. Fortunato, P. Tonello, F. B. Fernandes, P. Vilarinho and R. Martins, "Effect of Different Dopant Elements on the Properties of ZnO Thin Films," Vacuum, Vol. 64, No. 3-4, 2002, pp. 281-285. doi:10.1016/S0042-207X(01)00322-0

[11] S. B. Majumder, M. Jain, P. S. Dobal and R. S. Katiyar,
"Investigations on Solution Derived Aluminium Doped Zinc Oxide Thin Films," Materials Science and Engineering: $B$, Vol. 103, No. 1, 2003, pp. 16-25. doi:10.1016/S0921-5107(03)00128-4

[12] H. Kim, C. M. Gilmore, J. S. Horwitz, A. Piqué, H. Murata, G. P. Kushto, R. Schlaf, Z. H. Kafafi and D. B. Chrisey, "Transparent Conducting Aluminum-Doped Zinc Oxide Thin Films for Organic Light-Emitting Devices," Applied Physics Letters, Vol. 76, No. 3, 2000, pp. 259261. doi:10.1063/1.125740

[13] K. Yim, H. W. Kim and C. Lee, "Effects of Annealing on Structure, Resistivity and Transmittance of Ga Doped ZnO Films," Materials Science and Technology, Vol. 23, No. 1, 2007, pp. 108-112. doi:10.1179/174328407X158514

[14] O. Nakagawara, Y. Kishimoto, H. Seto, Y. Koshido, Y. Yoshino and T. Makino, "Moisture-Resistant ZnO Transparent Conductive Films with Ga Heavy Doping," Applied Physics Letters, Vol. 89, No. 9, 2006, Article No. 091904. doi:10.1063/1.2337542

[15] H. J. Bolink, E. Coronado, D. Repetto and M. Sessolo, "Air Stable Hybrid Organic-Inorganic Light Emitting Diodes Using $\mathrm{ZnO}$ as the Cathode," Applied Physics Letters, Vol. 91, No. 22, 2007, pp. 223501-223503. doi:10.1063/1.2809387

[16] D. H. Zhang, T. L. Yang, J. Ma, Q. P. Wang, R. W. Gao and H. L. Ma, "Preparation of Transparent Conducting ZnO:Al Films on Polymer Substrates by r. f. Magnetron Sputtering," Applied Surface Science, Vol. 158, No. 1-2, 2000, pp. 43-48. doi:10.1016/S0169-4332(99)00591-7

[17] Z. B. Fang, Z. J. Yana, Y. S. Tan, X. Q. Liu and Y. Y. Wang, "Influence of Post-Annealing Treatment on the Structure Properties of ZnO Films," Applied Surface Science, Vol. 241, No. 3-4, 2005, pp. 303-308. doi:10.1016/j.apsusc.2004.07.056

[18] P. Sagar, P. K. Shishodia, R. M. Mehra, H. Okada, A. Wakahara and A. Yoshida, "Photoluminescence and Absorption in Sol-Gel-Derived Zno Films," Journal of Luminescence, Vol. 126, No. 2, 2007, pp. 800-806.

[19] S. Y. Chu, W. Water and J. T. Liaw, "Influence of Postdeposition Annealing on the Properties of $\mathrm{ZnO}$ Films Prepared by RF Magnetron Sputtering," Journal of the European Ceramic Society, Vol. 23, No. 10, 2003, pp. 15931598. doi:10.1016/S0955-2219(02)00404-1

[20] V. Gupta and A. Mansingh, "Influence of Postdeposition Annealing on the Structural and Optical Properties of Sputtered Zinc Oxide Film," Journal of Applied Physics, Vol. 80, No. 2, 1996, pp. 1063-1072. doi: $10.1063 / 1.362842$

[21] J. F. Chang, W. C. Lin and M. H. Hon, "Effects of PostAnnealing on the Structure and Properties of Al-Doped Zinc Oxide Films," Applied Surface Science, Vol. 183, No. 1-2, 2001, pp. 18-25. doi:10.1016/S0169-4332(01)00541-4

[22] M. N. Islam, T. B. Ghosh, K. L. Chopra and H. N. Acharya, "XPS and X-Ray Diffraction Studies of AluminumDoped Zinc Oxide Transparent Conducting Films," Thin Solid Films, Vol. 280, No. 1-2, 1996, pp. 20-25. doi:10.1016/0040-6090(95)08239-5 
[23] G. E. Hammer and R. M. Shermenski, "The Oxidation of Zinc in Air Studied by XPS and AES," Journal of Vacuum Science \& Technology A, Vol. 1, No. 2, 1983, pp. 1026-1028. doi:10.1116/1.572331

[24] J. F. Moulder, W. F. Stickel, P. E. Sobol and K. D. Bomben, "Handbook of X-Ray Photoelectron Spectroscopy: A Reference Book of Standard Spectra for Identification and Interpretation of XPS Data," Physical Electronics, Eden Prairie, 1995.

[25] X. Q. Wei, B. Y. Man, M. Liu, C. S. Xue, H. Z. Zhuang and C. Yang, "Blue Luminescent Centers and Microstructural Evaluation by XPS and Raman in ZnO Thin Films Annealed in Vacuum, $\mathrm{N}_{2}$ and $\mathrm{O}_{2}$," Physica B: Condensed Matter, Vol. 388, No. 1-2, 2007, pp. 145-152. doi:10.1016/j.physb.2006.05.346

[26] Y. Takahashi, M. Kanamori, A. Kondoh, H. Minoura and Y. Ohya, "Photoconductivity of Ultrathin Zinc Oxide Films," Japanese Journal of Applied Physics, Vol. 33, No. 12, 1994, pp. 6611-6615. doi:10.1143/JJAP.33.6611

[27] G.-J. Fang, D.-J. Li and B.-L. Yao, "Influence of PostDeposition Annealing on the Properties of Transparent Conductive Nanocrystalline ZAO Thin Films Prepared by RF Magnetron Sputtering with Highly Conductive Ceramic Target," Thin Solid Films, Vol. 418, No. 2, 2002, pp. 156-162. doi:10.1016/S0040-6090(02)00733-2

[28] B. D. Ahn, S. H. Oh, C. H. Lee, G. H. Kim, H. J. Kim and S. Y. Lee, "Influence of Thermal Annealing Ambient on Ga-Doped ZnO Thin Films," Journal of Crystal Growth, Vol. 309, No. 2, 2007, pp. 128-133. doi:10.1016/j.jcrysgro.2007.09.014

[29] Y. Takahashi, M. Kananmori, A. Kondoh, H. Minoura and Y. Ohya, "Photoconductivity of Ultrathin Zinc Oxide Films," Japanese Journal of Applied Physics, Vol. 33, No. 12, 1994, pp. 6611-6615. doi:10.1143/JJAP.33.6611

[30] Q. B. Ma, Z. Z. Ye, H. P. He, L. P. Zhu, J. Y. Huang, Y. Z. Zhang and B. H. Zhao, "Influence of Annealing Temperature on the Properties of Transparent Conductive and Near-Infrared Reflective ZnO:Ga Films," Scripta Materialia, Vol. 58, No. 1, 2008, pp. 21-24. doi:10.1016/j.scriptamat.2007.09.009

[31] K. L. Chopra, "Thin Film Phenomena," McGraw-Hill, New York, 1969.

[32] D. Jiles, "Introduction to the Electronic Properties of Materials," Chapman and Hall, New York, 1994. doi:10.1007/978-1-4615-2582-0

[33] T. Minami, H. Nanto and S. Takata, "Optical Properties of Aluminum Doped Zinc Oxide Thin Films Prepared by RF Magnetron Sputtering," Japanese Journal of Applied Physics, Vol. 24, Part 2, 1985, pp. L605-L607. doi:10.1143/JJAP.24.L605

[34] E. Burstein, "Anomalous Optical Absorption Limit in InSb," Physical Review, Vol. 93, No. 3, 1954, pp. 632-633. doi:10.1103/PhysRev.93.632

[35] T. S. Moss, "The Interpretation of the Properties of Indium Antimonide," Proceedings of the Physical Society. Section B, Vol. 67, No. 10, 1954, pp. 775-782. doi:10.1088/0370-1301/67/10/306

[36] K. Bouzid, A. Djelloul, N. Bouzid and J. Bougdira, "Elec- trical Resistivity and Photoluminescence of Zinc Oxide Films Prepared by Ultrasonic Spray Pyrolysis," Physica Status Solidi (A), Vol. 206, No. 1, 2009, pp. 106-115. doi: $10.1002 /$ pssa.200824403

[37] D. C. Reynolds, D. C. Look, B. Jogai, J. E. Van Nostrand, R. Jones and J. Jenny, "Source of the Yellow Luminescence Band in GaN Grown by Gas-Source Molecular Beam Epitaxy and the Green Luminescence Band in Single Crystal ZnO," Solid State Communications, Vol. 106, No. 10, 1998, pp. 701-704. doi:10.1016/S0038-1098(98)00048-9

[38] P. K. Nayak, J. Yang, J. Kim, S. Chung, J. Jeong, C. Lee and Y. Hong, Journal of Physics D: Applied Physics, Vol. 42, No. 3, 2008, Article No. 035102.

[39] J. A. Sans, A. Segura, J. F. Sanchez-Royo, V. Barber, M. A. Hernandez-Fenollosa and B. Marib, "Correlation between Optical and Transport Properties of Ga-Doped ZnO Thin Films Prepared by Pulsed Laser Deposition," Superlattices and Microstructures, Vol. 39, No. 1-4, 2006, pp. 282-290. doi:10.1016/j.spmi.2005.08.050

[40] L.-P. Zhu, J.-S. Li, Z.-Z. Ye, H.-P. He, X.-J. Chen and B.-H. Zhao, "Photoluminescence of Ga-Doped ZnO Nanorods Prepared by Chemical Vapor Deposition," Optical Materials, Vol. 31, No. 2, 2008, pp. 237-240. doi:10.1016/j.optmat.2008.03.015

[41] B. J. Jin, S. Im and S. Y. Lee, "Violet and UV Luminescence Emitted from ZnO Thin Films Grown on Sapphire by Pulsed Laser Deposition," Thin Solid Films, Vol. 366, No. 1-2, 2000, pp. 107-110. doi:10.1016/S0040-6090(00)00746-X

[42] K. Vanheusden, W. L. Warren, C. H. Seager, D. R. Tallant, J. A. Voigt and B. E. Gnade, "Mechanisms Behind Green Photoluminescence in ZnO Phosphor Powders," Journal of Applied Physics, Vol. 79, No. 10, 1996, pp. 7983-7970. doi:10.1063/1.362349

[43] D. C. Look and B. Claflin, "P-Type Doping and Devices Based on ZnO," Physica Status Solidi (B), Vol. 241, No. 3, 2004, pp. 624-630. doi:10.1002/pssb.200304271

[44] H. J. Egelhaaf and D. Oelkrug, "Luminescence and Nonradiative Deactivation of Excited States Involving Oxygen Defect Centers in Polycrystalline ZnO," Journal of Crystal Growth, Vol. 161, No. 1-4, 1996, pp. 190-194. doi:10.1016/0022-0248(95)00634-6

[45] P. M. R. Kumar, C. S. Kartha, K. P. Vijayakumar, F. Singh, D. K. Avasthi, T. Abe, Y. Kashiwaba, G. S. Okram, M. Kumar and S. Kumar, "Modifications of $\mathrm{ZnO}$ Thin Films under Dense Electronic Excitation," Journal of Applied Physics, Vol. 97, No. 1, 2005, Article No. 013509. doi:10.1063/1.1823574

[46] Y. H. Tong, Y. C. Liu, S. X. Lu, L. Dong, S. J. Chen and Z. Y. Xiao, "The Optical Properties of ZnO Nanoparticles Capped with Polyvinyl Butyral," Journal of Sol-Gel Science and Technology, Vol. 30, No. 3, 2004, pp. 157-161. doi:10.1023/B:JSST.0000039500.48283.5a

[47] X. Q. Wei, B. Y. Man, M. Liu, C. S. Xue, H. Z. Zhuang and C. Yang, "Blue Luminescent Centers and Microstructural Evaluation by XPS and Raman in $\mathrm{ZnO}$ Thin Films Annealed in Vacuum, $\mathrm{N}_{2}$ and $\mathrm{O}_{2}$," Physica B: Condensed Matter, Vol. 388, No. 1-2, 2007, pp. 145-152. 
doi:10.1016/j.physb.2006.05.346

[48] K. Prabakar, C. Kim and C. Lee, "UV, Violet and BlueGreen Luminescence from RF Sputter Deposited ZnO:Al Thin Films," Crystal Research and Technology, Vol. 40, No. 12, 2005, pp. 1150-1154. doi:10.1002/crat.200410508

[49] D. Wang. H. W. Seo, C. C. Tin, M. J. Bozack, J. R. Williams, M. Park, N. Sathitsuksanoh, A.-J. Cheng and Y. H. Tzeng, "Effects of Postgrowth Annealing Treatment on the Photoluminescence of Zinc Oxide Nanorods," Journal of Applied Physics, Vol. 99, No. 11, 2006, pp. 113509113513. doi:10.1063/1.2200593

[50] S. A. Studenikin and M. Cocivera, "Time-Resolved Luminescence and Photoconductivity of Polycrystalline $\mathrm{ZnO}$ Films," Journal of Applied Physics, Vol. 91, No. 8, 2002, pp. 5060-5065. doi:10.1063/1.1461890 